\title{
Influence of Sociodemographic Factors in Hematological Parameters during Treatment of Chronic Hepatitis C.
}

\author{
Elza Cristina Miranda da Cunha ${ }^{1,2}$, Bruna Brandão Farias ${ }^{1}$, Natália Xavier Carvalho ${ }^{1}$, Indiara Viegas ${ }^{1}$, \\ Andréia Rosa dos Santos ${ }^{1}$, William Silva Ribeiro ${ }^{1}$, Christian Loret de Mola ${ }^{3}$, Lysandro Alsina Nader ${ }^{2}$, \\ Gabriele Ghisleni $^{1}$
}

${ }^{1}$ Laboratório de Neurociências Clínicas, Programa de Pós-Graduação em Saúde e Comportamento, Universidade Católica de Pelotas, Pelotas, Brazil

${ }^{2}$ Faculdade de Medicina, Universidade Federal de Pelotas, Pelotas, Brazil

${ }^{3}$ Programa de Pós-Graduação em Epidemiologia, Universidade Federal de Pelotas, Brazil

Corresponding Author: Elza Cristina Miranda da Cunha; ecmirandacunha@gmail.com

Received 25 June 2019;

Accepted 21 August 2019;

Published 26 August 2019

\begin{abstract}
Introduction: Adverse effects of peginterferon/ribavirin therapy and sociodemographic factors are known to modify hematological parameters. The present study was aimed to evaluate the impact of sociodemographic characteristics on laboratorial blood profile during treatment of Chronic Hepatitis C (CHC). Method: This is a Cohort of 136 patients with CHC in treatment with peginterferon/ribavirin. Sociodemographic and laboratorial profile were collected in the baseline, $4^{\text {th }}$ and $12^{\text {th }}$ weeks of treatment. Results: The mean age of patients was $53 \pm 11.7$ years, 78 $(57.4 \%)$ were men, $119(87.5 \%)$ were Caucasian. Hemoglobin levels decreased along the treatment from baseline $(14.3 \pm 1.7 \mathrm{~g} / \mathrm{dL})$ to $4^{\text {th }}(12.0$ $\pm 1.8 \mathrm{~g} / \mathrm{dL})$ and $12^{\text {th }}(11.5 \pm 1.6 \mathrm{~g} / \mathrm{dL} ; \mathrm{p}=0.001)$. Leukocytes values also decreased from baseline to $4^{\text {th }}$ and $12^{\text {th }}$ weeks of treatment $(6805.6$ $\pm 6574.3 / \mathrm{mm}^{3} ; 3827.6 \pm 1650.3 / \mathrm{mm}^{3}$ and $3541 \pm 2056 / \mathrm{mm}^{3}$, respectively; $\left.\mathrm{p}=0.001\right)$, as well as platelets values $\left(175168.06 \pm 60846.7 \mathrm{~mm}^{3}\right.$, $138612.06 \pm 59356.6 / \mathrm{mm}^{3}$, and $127279.1 \pm 56333.6 / \mathrm{mm}^{3}$, respectively; $\left.\mathrm{p}=0.001\right)$. Men had greater values of hemoglobin along treatment $(\mathrm{p}=0.001)$, while older $(\mathrm{p}=0.012)$ and non-Caucasian patients $(\mathrm{p}=0.008)$ have lower values. Platelets levels were reduced in older $(\mathrm{p}=0.007)$ and men patients $(\mathrm{p}=0.001)$ along treatment. Conclusion: social factors as sex, age, and ethnicity, showed greater impact on hematological variables during CHC treatment, revealing an important point to be considered since may influence the management of treatment.
\end{abstract}

Keywords: Hepatitis C treatment; hematological parameters; sociodemographic factors

\section{Introduction}

Chronic Hepatitis $\mathrm{C}$ (CHC) virus infection, one of the most common causes of chronic liver disease, is a major global health problem and is associated with substantial morbidity and mortality from sequelae, such as liver cirrhosis and hepatocellular carcinoma (HCC). ${ }^{[1,2]}$ The course of $\mathrm{CHC}$ infection and the fibrosis progression rate varies extremely, and is influenced by host, viral, and environmental factors. ${ }^{[3]}$

Proper and effective antiviral treatment is associated with a reduction in portal hypertension, hepatic decompensation, HCC, liver transplantation, and liver-related mortality. ${ }^{[3]}$ It has been shown that $27 \%$ of infected CHC patients develop cirrhosis while 25\% develops HCC. ${ }^{[1]}$ Afterwards, therapy consisting in Peginterferon (PegIFN) combined to Ribavirin (RBV) enhanced sustained virological response (SVR) rates of $42-52 \% .^{[3]}$
Adverse effects of PegIFN and RBV combination therapy affect nearly all the patients with $\mathrm{CHC}$ who receive the therapy, impact negatively patient's quality of life and lead to premature termination of therapy in up to $8.7 \%$ of cases. ${ }^{[4,5]}$ The common side effects are changes in blood composition, leading to thrombocytopenia, leukopenia and anemia. ${ }^{[6,7]}$ PegIFN therapy is also observed to suppress the bone marrow leading to cytopenia ${ }^{[8]}$. In most cases, platelet count decrease due the therapy of PegIFN and RBV but in severe condition may lead to bleeding, when the therapy need to be stopped. ${ }^{[5]}$ However, only few studies have evaluated the predictors and risk factors for the degree of hemoglobin (HB) reduction with this treatment regimen. ${ }^{[1,9]}$ Fried et al. (2002) showed that the HB levels dropped to its nadir after approximately 4 weeks of antiviral treatment. ${ }^{[10]}$ At this point the treatment dosage needs to be adjusted or stopped altogether. ${ }^{[5]}$

Hematological toxicities may be improved by dose reduction; however, it carries the risk of a treatment response. ${ }^{[5]}$ In order to 
reduce the chances of drug induced disorders associated with HCC therapy and to maximize the desired therapeutic outcomes, effective laboratory tests and symptomatic monitoring of the patients must be carried out during the treatment. ${ }^{[6]}$

Moreover, identify patients who are at risk of developing hematological abnormalities before start antiviral therapy, can help the management of treatment and timely decisions for additional interventions that can improve patient outcomes. ${ }^{[2]}$ Thus, the present study aimed to evaluate the influence of the patient's sociodemographic characteristics along the treatment over blood composition parameters in order to improve adherence, minimize side effects and increase SVR.

\section{Methodology}

\section{Study design}

This study is a convenience cohort of CHC patients followed-up by 12 weeks during the antiviral therapy. The diagnosis of $\mathrm{CHC}$ was established by the presence of Hepatitis C Virus (HCV) antibody on ELISA, and confirmed by the presence of HCV RNA, using qualitative polymerase chain reaction assays.

The study was performed from February 2013 to May 2016, in Gastroenterology Outpatient Clinic - Injectable Medication Monitoring and Application Center (CAMMI) - in Medicine Faculty of Federal University of Pelotas (UFPel), Rio Grande do Sul, Brazil. The sample consisted of 136 CHC patients, with treatment indication according to the Treatment Protocol of Viral Hepatitis of the Health Ministry (2011-2015). ${ }^{[11]}$ The treatment was based in drugs used for the CHC in Brazil, PegIFN and RBV (mean dose of $13 \mathrm{mg} / \mathrm{kg} /$ day) for 24 to 48 weeks depending on the virus genotype, viral load and fibrosis degree. The health professionals who attend the service weekly monitored the adherence to treatment through direct contact with the patients. A sociodemographic questionnaire was applied at the baseline, before the beginning of the antiviral therapy. Additional information's of the study were described in Cunha et al., (2015). ${ }^{[12]}$

All ethical principles established by the National Health Council in Resolution No. 466/12 were respected and in accordance with the 1964 Helsinki declaration and its later amendments. All patients who agree to participate in the research provided a written informed consent. The Catholic University's Ethics Committee (151.642 and 658.087) approved the study.

\section{Laboratorial analysis}

Laboratorial data were collected from patients along the treatment through medical records, and were routinely requested. HB, leucocytes and platelets were analyzed on the equipment SYSMEX XS-1000i according to manufacturer's instructions at the hospital laboratory of UFPEL. The HB reference values for women are 12$16 \mathrm{~g} / \mathrm{dL}$ and for men are $13.5-18 \mathrm{~g} / \mathrm{dL}$. The other hematological parameters analyzed have no different reference values according to sociodemographic characteristics.

\section{Statistical analysis}

Data were analyzed in STATA 14.0 considering a $\mathrm{p}$ value $<0.05$. Simple frequency was used to sample description, and the analysis of differences between laboratorial blood profile along the treatment was made by ANOVA of repeated measures. General liner regression was used to evaluate the relationship between sociodemographic characteristics and laboratorial blood profile along the $\mathrm{CHC}$ treatment.

\section{Results}

Table 1: Sociodemographic and clinical characteristics of Hepatitis C patients before treatment

\begin{tabular}{|ll|}
\hline Variable & N $(\%)$ or Mean $( \pm$ SD) \\
\hline Gender Male & $78(57.4 \%)$ \\
Caucasian Ethnicity & $119(87.5 \%)$ \\
First treatment & $106(77.9 \%)$ \\
Age (years) & $53 \pm 11.7$ \\
Years of study & $10 \pm 5.2$ \\
Marital status (\% of Married) & $82(60.3 \%)$ \\
Contamination mode & \\
Blood transfusion & $38(27.9 \%)$ \\
Drugs & $19(14 \%)$ \\
Unknow & $64(47.1 \%)$ \\
Currently working & $70(51.5 \%)$ \\
Type of medication for hepatites C & \\
Peginterferon & $124(91.2 \%)$ \\
Interferon alpha & $12(8.8 \%)$ \\
Genotype & \\
1 & $59(45 \%)$ \\
2/ 3 & $72(55 \%)$ \\
\hline Total & $\mathbf{1 3 6}$ \\
\hline
\end{tabular}

Displayed as mean \pm standard deviation (SD) or $n$ and $\%$. Descriptive analysis were made by single frequency.

Table 2: Mean values of laboratorial blood profile during Hepatitis $\mathrm{C}$ treatment with peginterferon/ribavirin

\begin{tabular}{|l|l|l|l|l|}
\hline Laboratorial analytics & Pre-treatment & $\mathbf{4}^{\mathbf{a}}$ week & $\mathbf{1 2}^{\mathbf{a}}$ week & P value \\
\hline Hemoglobin & $14.3 \pm 1.7 \mathrm{~g} / \mathrm{dL}$ & $12.0 \pm 1.8 \mathrm{~g} / \mathrm{dL}$ & $11.5 \pm 1.6 \mathrm{~g} / \mathrm{dL}$ & $<0.001$ \\
\hline Leukocytes & $6805.6 \pm 6574.3 / \mathrm{mm}^{3}$ & $3827.6 \pm 650.3 / \mathrm{mm}^{3}$ & $3541.0 \pm 2056.0 / \mathrm{mm}^{3}$ & $<0.001$ \\
\hline Platelets & $175168.0 \pm 60846.7 / \mathrm{mm}^{3}$ & $138612.0 \pm 59356.6 / \mathrm{mm}^{3}$ & $127279.1 \pm 56333.6 / \mathrm{mm}^{3}$ & $<0.001$ \\
\hline Viral load & $226631058.8 \pm 5268418.4 \mathrm{IU} / \mathrm{mL}$ & $75479.4 \pm 436246.3 \mathrm{IU} / \mathrm{mL}$ & $63654.8 \pm 344.06 \mathrm{IU} / \mathrm{mL}$ & 0.052 \\
\hline
\end{tabular}

All data are presented as mean \pm standard deviation $(S D)$. The significance level of $p$ value for Laboratorial analytics was set at 0.05 according to repeated measures ANOVA.

Table 3: Regression Coefficient between sociodemographic characteristics and laboratorial analytics along the Hepatitis $\mathbf{C}$ treatment

\begin{tabular}{|l|l|l|l|l|}
\hline Variables & Hemoglobin & & Platelets & \\
\hline Age (Older) & Coefficient $($ IC95\%) & P value & Coefficient (IC95\%) & P value \\
\hline Ethncity (Non- & $-0.02(-0.04--0.00)$ & 0.012 & $-1037.33(-1791.23--283.43)$ & 0.007 \\
\hline Caucasian) & $-0.84(-1.47--0.22)$ & 0.008 & $14879.49(-10908.24--40667.22)$ & 0.258 \\
\hline Sex (Men) & $1.20(0.76--1.64)$ & 0.001 & $-40034.91(-57763.77--22306.05)$ & 0.001 \\
\hline
\end{tabular}

Reference group: Younger, Caucasian and Women subjects. $P \leq 0.05$ was considered statistically significant. 
The mean age of patients was $53 \pm 11.7$ years, $78(57.4 \%)$ were men, $82(60.3 \%)$ were married, $119(87.5 \%)$ Caucasian, and the mean years of study was $10 \pm 5.2$ years (Table 1 ). The mean values of $\mathrm{HB}$ decrease in the $4^{\text {th }}(12.0 \pm 1.8 \mathrm{~g} / \mathrm{dL})$ and $12^{\text {th }}(11.5 \pm 1.6 \mathrm{~g} / \mathrm{dL})$ week of treatment from the baseline $(14.3 \pm 1.7 \mathrm{~g} / \mathrm{dL} ; \mathrm{p}<0.001)$. Leukocyte values decrease from the baseline $\left(6805.6 \pm 6574.3 / \mathrm{mm}^{3}\right)$ in the $4^{\text {th }}\left(3827.6 \pm 1650.3 / \mathrm{mm}^{3}\right)$ and $12^{\text {th }}\left(3541 \pm 2056 / \mathrm{mm}^{3}\right)$ week of treatment $(\mathrm{p}<0.001)$, as well as platelets values in the $4^{\text {th }}$ $\left(138612.06 \pm 59356.6 / \mathrm{mm}^{3}\right)$ and $12^{\text {th }}\left(127279.1 \pm 56333.6 / \mathrm{mm}^{3}\right)$ week of treatment related to the baseline values $\left(175168.06 \pm 60846.7 / \mathrm{mm}^{3} ; \mathrm{p}<0.001\right)$ (Table 2). Regarding viral load, we showed a tendency of decrease in the $4^{\text {th }}$ $(75479.4 \pm 436246 . \mathrm{IU} / \mathrm{mL})$ and $12^{\text {th }}(63654.8 \pm 344.06 \mathrm{IU} / \mathrm{mL})$ week along the treatment from baseline $(22663105.8 \pm 5268418.4 \mathrm{IU} / \mathrm{mL}$; $\mathrm{p}=0.052)$ (Table 2).

General linear regression between sociodemographic characteristics and laboratorial blood profile along the $\mathrm{CHC}$ treatment are showed in Table 3. The data indicate that men had greater $\mathrm{HB}$ values during treatment compared to women [coef: 1.20 (CI 0.76 - 1.64); $\mathrm{p}=0.001$ ]; older showed less $\mathrm{HB}$ values than younger patients [coef: -0.02 (CI -0.04- -0.00$) ; \mathrm{p}=0.012$ ]; and non-Caucasian patients had less HB values than Caucasians [coef: -0.84 (CI -1.47- -0.22); $\mathrm{p}=0.008]$. No significant differences were observed for marital status $(\mathrm{p}=0.258)$, and years of education $(\mathrm{p}=0.742)$ (Data not shown). When assessed total leukocytes no significant differences were observed for $\operatorname{sex}(p=0.174)$, age $(\mathrm{p}=0.616)$, marital status $(\mathrm{p}=0.430)$, ethnicity $(\mathrm{p}=0.347)$ and years of education ( $\mathrm{p}=0.542)$ (Data not shown). For platelets evaluation, results demonstrated that men had greater loss of platelets during treatment compared to women [coef: -40034.91 (CI -57763.77 - 22306.05); $\mathrm{p}=0.001$ ]; older patients showed less platelets values than younger [coef: -1037.33 (CI - 1.791.23 - -283.43); $\mathrm{p}=0.007$ ]; and no difference for marital status $(\mathrm{p}=0.510)$, ethnicity $(\mathrm{p}=0.258)$, and years of education $(\mathrm{p}=0.871)$ was demonstrated. Finally, no influence was observed between sex, age, marital status, ethnicity and years of education in relation to viral load (data not showed).

\section{Discussion}

CHC is a pathology that affects several people worldwide and its treatment is of fundamental importance to stop the evolution of the disease, preventing the progression to cirrhosis and HCC. However, laboratorial blood profile can be affected by the PegIFN and RBV therapy. ${ }^{[5]}$ In this context, is important identify patients prone to develop hematological alterations during the treatment to optimize the therapy in the early phase of treatment. Here, we also suggest that hematological markers can be modulated by sociodemographic characteristics of patients, showing that sex, ethnicity and age may change these parameters in CHC patients during the treatment.

Sex differences for HB and hematocrit levels are consistent with previous reports where men have higher HB levels than women, which can be explained probably by the effects of androgens on erythropoiesis that increases the number of circulating red blood cells with a resultant hemodilution. ${ }^{[13,14,15,16]}$ Several studies also show differences in platelets counts according to ethnicity, sex and age $^{[14,17,18]}$ as well as in leukocytes. ${ }^{[14]}$ At this point, there are only few studies linking sociodemographic characteristics on hematological parameters even considering $\mathrm{CHC}$ patients.

Anemia is defined as a decrease in HB level up to $2-3 \mathrm{~g} / \mathrm{dL}$ or more from the baseline value. ${ }^{[6]}$ The recommended management of anemia during $\mathrm{CHC}$ combination therapy is reduce the RBV dose if HB levels reach values $<10 \mathrm{~g} / \mathrm{dL}^{[3,19]}$ Therefore, the use of erythropoietin has been studied in the context of correcting the inadequate haemotopoiesis, improving the anemia in patients treated with combination therapy. ${ }^{[8,19,20]}$

In this study, significant reduction in $\mathrm{HB}$, platelets and leukocytes values were observed after $4^{\text {th }}, 8^{\text {th }}$, and $12^{\text {th }}$ weeks of therapy, where sex, age and ethnicity may influence only HB and platelet values. Similar to our results, previous studies showed no influence of these sociodemographic variables on leukocytes values. ${ }^{[6]}$ Related to HB values, our results showing that men had higher HB values than women along the treatment are controversial with literature data reporting lower levels of $\mathrm{HB}$ for men. ${ }^{[1]}$ Rafique and collaborators (2017) also showed that men have significant reduction in HB levels after $4^{\text {th }}, 8^{\text {th }}, 12^{\text {th }}$ and $16^{\text {th }}$ weeks of therapy related to women. ${ }^{[6]}$ However, the results are not conclusive, with studies showing reduced values of $\mathrm{HB}$ after three months of therapy, with no influence of sex..$^{[5,8]}$ In our study, older and nonCaucasian patients had lesser HB values in relation to the younger and Caucasians subjects along the treatment. Similar to our findings, studies have demonstrated that advanced age may be a prognostic factor for the incidence of anemia, ${ }^{[21,22]}$ although other studies reveals no relationship between age and $\mathrm{HB} .{ }^{[8]}$

In general for CHC patients, thrombocytopenia is mild in most cases, amounting to a decrease in peripheral platelet count of $10 \%$ to $50 \%$, but, when severe, can lead to bleeding complications and discontinuation of PegIFN. ${ }^{[22]}$ Around $4-6 \%$ of patients receiving PegIFN and RBV requires reductions of medication dose for attenuates the thrombocytopenia. ${ }^{[10]}$ In fact, dose reduction is advised when platelet counts fall below $50.000 / \mathrm{dL}$, although discontinuation of therapy is usually unnecessary. ${ }^{[23]}$ When patients' platelets were evaluated, we found that men and older subjects showed decreased levels of platelet along treatment in relation to women and younger ones. Recently, a study showed statistically significant reduction in platelet count observed in men at 4 th, 8 th, $12^{\text {th }}$ and $16^{\text {th }}$ week of therapy, but only after $16^{\text {th }}$ week for women. ${ }^{[6]}$ However, according to baseline data in Rehman' study, platelets count in CHC patients for both sex did not differs significantly. ${ }^{[5]}$

These findings are important to predict which patients will be more susceptible to hematological changes leading to anemia, leukopenia and thrombocytopenia, allowed a more intensive monitoring of patients to achieve the early treatment of these complications. In case of adverse side effects of such therapy, timely modification of dose or stopping the therapy may be lifesaving. This, in turn, can help to identify patients who may benefit from aggressive monitoring as well as the use of growth factors in this patient population. Moreover, data from literature about this appointment are scares and of extremely importance to predict a personalized therapy for $\mathrm{CHC}$ patients.

\section{Acknowledgements}

This study was supported by CNPq and CAPES Brazil.

\section{Competing interests}

No competing financial interests exist. 
Chronic Hepatitis C (CHC), hepatocellular carcinoma (HCC), Peginterferon (PegIFN), Ribavirin (RBV), sustained virological response (SVR), hemoglobin (HB), Hepatitis C Virus (HCV), Faculty of Federal University of Pelotas (UFPel),

\section{Funding}

This study was supported by CNPq and CAPES Brazil.

\section{References:}

[1] Hu CC, Weng CH, Lin CL, Tien HC, Kuo YL, Chien CH et al. Predictors of Changes in Hemoglobin Levels in Patients with Chronic Hepatitis C Treated with Ribavirin Plus Pegylated Interferon- $\alpha$. Renal Failure 2012; 34(4): 429-434.

[2] Nachnani JS, Rao G, Bulchandani D, Pandya PK, Alba LM. Predictors of hematological abnormalities in patients with chronic hepatitis $\mathrm{C}$ treated with interferon and ribavirin. Ann Hematol 2010; 89: 121-125.

[3] Miotto, L.C. Mendes, L.P. Zanaga, E.S.L. Goncales, M.S.K. Lazarini, M.N., Goncales Jr., R.S.B. Stucchi and A.G. Vigani. Predictors of early treatment discontinuation and severe anemia in a Brazilian cohort of hepatitis C patients treated with firstgenerationprotease inhibitors. Braz J Med Biol Res 2016; 49(7):1-9. doi: 10.1590/1414-431X20165300.

[4] Ogawa, E, Furusyo N, Kajiwara E, Nomura H, Kawano A, Takahashi, K Dohmen. Comparative safety study on severe anemia by simeprevir versus telaprevir-based triple therapy for chronic hepatitis C. $J$ Gastroenterol Hepatol 2015; 1309-1316.

[5] Rehman AU, Ali F, Ali M, Alam I, Khan AW. Changes in Hematological Parameters with Pegylated Interferon in Chronic Hepatitis C Virus Infected Patients. Asian Pac J Cancer Prev 2016; 17 (5), 2485-2490.

[6] Rafique G, Bukhsh A, Gul A, Khiljee S, Ashraf M and Omer MO. Hematologic adverse effects and efficacy monitoring in chronic Hepatitis $\mathrm{C}$ patients treated with interferon and ribavirin combination therapy. Pak. J. Pharm. Sci. 2017; 30(1): 011-016

[7] Franceschi L, Fattovich G, Turrini F, Ayi K, Brugnara C, Manzato F, Noventa F, et al. Hemolytic Anemia Induced by Ribavirin Therapy in Patients With Chronic Hepatitis C Virus Infection: Role of Membrane Oxidative Damage. Hepatology 2000; 31:997-1004.

[8] Jadoon SA, Ahmed A, Jadoon HA. Effect of Standard interferon and Ribavirin on haemoglobin level in Hepatitis C patients. J Ayub Med Coll Abbottabad 2014; 26 (4):510-2.

[9] Sulkowski M. S, Wasserman R, Brooks L, Ball L and Gish R. Changes in haemoglobin during interferon alpha$2 \mathrm{~b}$ plus ribavirin combination therapy for chronic hepatitis C virus Infection. J Viral Hepat, 2004; 11: 243250.

[10] Fried MW, Hiffman M, Reddy KRA, Smith C, Arinos GM. Peginterferon alfa-2a plus Ribavirin for Chronic Hepatitis C Virus Infection. N Engl J Med 2002; 347(13): 975-982.
[11] Protocolo Tratamento Hepatite C e Coinfecções. Ministério da Saúde. Brazil 2011- 2015.

[12] Cunha ECM, Behrensdorf MF, Bavaresco V, Zambrano DN, Bellini J, Kaster MP, Spessato B, Ghisleni G. Genotype 1 of hepatitis $\mathrm{C}$ virus increases the risk of major depression: a 12-week prospective study. Gen Hosp Psychiatry 2015;(37): 283-287.

[13] Segolodi TM, Henderson LM, Rose CH, Turner KT, Zeh C, Fonjungo PN. Normal Laboratory Reference Intervals among Healthy Adults screened for a HIV Pre-Exposure Prophylaxis - Clinical Trial in Botswana. PLOS ONE 2014; 9(4): e93034. doi: 10.1371/journal.pone.0093034 published online first 1 April 2014.

[14] Mcllhagger R, Gow AJ, Brett CE, Corley J, Taylor M, Deary IJ and Starr JM. Differences in the haematological profile of healthy 70 year old men and women: normal ranges with confirmatory factor analysis. BMC Blood Disorders 2010; 10:4.

[15] Dosoo DK, Kayan K, Adu-Gyasi D, Kwara E, Ocran J, Osei-Kwakye. Haematological and Biochemical Reference Values for Healthy Adults in the Middle Belt of Ghana. PLoS ONE 2012 7(4): e36308. doi: 10.1371/journal.pone.0036308 published on line first April 2012.

[16] Biino G, Santimone I, Minelli C, Sorice R, Frongia B, Traglia M. Age- And Sex-Related Variations in Platelet Count in Italy: A Proposal of Reference Ranges Based on 40987 Subjects' Data. PLoS ONE 2013; 8(1): e54289. doi: 10.1371/journal.pone.0054289 published on line first 1 January 2013.

[17] Segal JB, Moliterno AR. Platelet Counts Differ by Sex, Ethnicity, and age in the United States. Ann Epidemiol 2006; 16: 123-130.

[18] Barbara J Bain. Ethnic and sex differences in the total and differential white cell count and platelet count. J Clin Pathol 1996; 49: 664-666.

[19] Aspinall RJ, Pockros PJ. Review article: the management of side-effects during therapy for hepatitis C. Aliment Pharmacol Ther 2004; 20: 917-929.

[20] Dieterich DT and Spivak JL. Hematologic Disorders Associated with Hepatitis C Virus Infection and Their Management. Clinical Infectious Diseases 2003; 37: 533-41.

[21] Snoeck E, Wade JR, Duff F, Lamb M \& Jorga K. Predicting sustained virological response and anaemia in chronic hepatitis $\mathrm{C}$ patients treated with peginterferon alfa-2a (40KD) plus ribavirin. Br J Clin Pharmacol 2006; 62(6): 699-709.

[22] Iashin H, Shaheen YA, Metwally MA, El-Feky HH, Hegab MF, Abbas SM. Incidence and predictors of hematological side effects in chronic HCV Egyptian patients treated with Pegylated interferon and ribavirin. Indian J Gastroenterol 2013; 32(5): 316-23. 23. doi: 10.1007/s12664-013-0336-z.published on line first in 29 May 2013.

[23] Ong JP and Younossi ZM. Managing the hematologic side effects of antiviral therapy for chronic hepatitis C: Anemia, neutropenia, and thrombocytopenia. Cleve Clin J Med 2004; 71 (3): 17-21. 